\title{
Research on the substantive cognizance condition for unfair internet competition in china
}

\begin{abstract}
This paper focuses on the study of substantive identification of the unfair competition in China's Internet environment from the perspective of typed clauses. The application of unfair Internet competition cases and typed clauses in China are discussed with the help of literature and articles summarization, case studies and statistics analysis. The results show that the types of unfair competition are still of practical significance under the Internet environment. Meanwhile, the problem of new types of unfair competitions in the Internet environment needs to be solved by new regulatory paths, including the generalization of new typical behavior, the boundary definition between competition and innovation, and so on
\end{abstract}

Keywords: internet, unfair competition, substantive cognizance condition, typed clauses
Volume 2 Issue I - 2018

\author{
Zhe Wang, Bingsheng Zhang
}

Law School of Ningbo University, China

Correspondence: Zhe Wang, Assistant Professor, Law School of Ningbo University, China, Email zhejubiji@I63.com

Received: December 19, 2017| Published: January 22, 2018

\section{Introduction}

When talking about unfair competition, business ethics has to be involved, which means to judge whether the competition is fair or not is very much ethical debate. And its connotation is also evolving along with the development of social economy, so in this sense, defining "fair competition" or "unfair competition" is very difficult. Therefore, whether it is related to international conventions, or national laws, what is unfair competition is illustrated or identified by way of listing specific examples. China's Internet has experienced three development upsurges and has gradually developed from the free competition to the stage of the monopolistic competition, or even oligopoly. China's cognizance of unfair competition is mainly based on the Anti-Unfair Competition Law of the People's Republic of China, which stipulates typed clauses and general clauses. This paper intends to explore the substantive cognizance condition on unfair competition from the angle of "typed clauses." While the "typed clauses" are characterized by inductive and operable behavior in the course of the cognizing unfair competition, the Internet environment leads to diversified acts of unfair competition. Thus it is difficult and complicated to identify new unfair competition effectively; this also has become the focus and difficulty of practical work. In the current Internet environment, the value of typed clauses and how to use the "typed clauses" to identify unfair competition is the key point of this paper.

\section{Typed clauses}

\section{Definition of typed clauses}

Based on the knowledge and ethical standards of our time, the Typed Clauses give the general cognizance conditions of unfair competition. The research on typification not only provides theoretical support for the relevant legislation but also provides a predictable tool for the application of justice.

Types: A certain type is formed by some basic characteristic structure. The formation and evolution of legal norm is essentially the result of typification, and its formulation is also realized through the construction of types. "When the abstract - the general concept and its logical system are not sufficient to grasp the life phenomenon, or the various representative forms of the meaningful context, the first form of subsidy thinking that comes into our mind is 'type'. The construction of a type, in fact, is a philosophical method by which the subjects were arranged in the same genus with a combined standard between characteristics of things and the value of the subject ${ }^{2}$. Many new types of unfair competition emerge in the Internet age. One scholar listed seven types of unfair competition: domain name cybersquatting, improper linking, embedding technology, software attacks, forced advertising, "shameless software", and unauthorized changes to others' home page ${ }^{3}$.

Typification: As philosophical thinking, typification is a fixed combination which searches for social objects (or phenomena) attributes in the entire variable system that belongs to a social object (or phenomenon $)^{4}$. "How to type is with the help of typification method, that is "by looking for distinguishing status between events or activities in a relational model to explain them ${ }^{5}$. Wang Liming (2011) assumes that the method of typification is, to sum up, the common attributes of a specific concept and to achieve the reification of concept ${ }^{6}$. How is the unfair competition typified in the Internet environment? The network economy and the traditional economy are inextricably linked, and many network economic activities are the extension of traditional economic activities in the network background, such as traditional trading transactions nowadays are done through "Taobao" and other

\footnotetext{
${ }^{1}$ Carle Larenz (2003) Translated by Chen Aie Methodology of Law, Commercial Press, China, pp. 337.

${ }^{2} \mathrm{Lin} \mathrm{Li} \mathrm{(2000)} \mathrm{Methodology} \mathrm{of} \mathrm{Law} \mathrm{and} \mathrm{Dworkin,} \mathrm{China} \mathrm{University} \mathrm{of}$ Political Science and Law Press, pp. 124-142.

${ }^{3}$ Hou Xia (2010) Legal regulation new type of unfair competition under the internet environment. Journal of Anhui University of Technology, China.

${ }^{4} \mathrm{Li}$ Ke (2003) Typified Thinking and Its Methodological Significance-Taking Traditional Abstract Thinking as Reference. Jinling Law Review, China.

${ }^{5}$ Mark Bruce, Li Mingxing, Chen Yimin (1990): "Economic Methodology," Peking University Press, Page 139.

${ }^{6}$ Wang Liming (2011): "Methodology of Law," China Renmin University Press, Page 422.
} 
sites for online transactions and so on. Except with network-specific factors, most network unfair competitions also have the essence of traditional unfair competition. Therefore, the typification of unfair network competition should be based on the essence analysis of the specific behavior, as far as possible existing classification could be used to determine the type.

Typed clauses: Typed Clauses refer to the universal, typical clauses abstracted from specific behavior by way of induction or deduction with legal nature. The typed Clauses are a negative evaluation of the abuse of free competition, but not all negative allegations towards the abuse of free competition are embodied in the typed clauses. Typed Clauses are only one of the most typical and uncontested part. The typed clauses of anti-unfair competition law are the explicit performance of the negative evaluation beforehand ${ }^{7}$.

\section{Existing meaning of typed clauses}

The induction of theory: Typed Clauses classify systematically and professionally the existing unfair competition types, and judgment and identification are greatly enhanced in practice, while classification problems are also solved in the study. Firstly, the principle should be followed, while its content should be enriched. The purpose of the law enforcement is to ensure fairness and justice. As an effective way and bridge, typification can help to check the implementation of fairness and justice; Secondly, typification can also provide warning and reference, that is clauses contrary to the spirit of fairness, and justice legislation can be validated effectively.

Practical Usability: The life of the law lies not in the logic, but the experience," the vitality of law is achieved through its application. "General clauses + Typed clauses" has become a legislative trend, it is used as a legislative form both in the "Anti-Unfair Competition Law" and "Tort Law." The specification of Typed Clauses complemented the rigidity and applied difficulty of the General Clauses, while extending the applicable limitations of the General Clauses, providing of possibilities for commercial practices and customization practices ${ }^{8}$.

The efficiency of the amendment: The introduction of the Typed Clauses ensured the flexibility and tension of legislation and justice, which is of great significance to the construction of a relatively stable legal system. The legal nature of the Typed Clauses determines the actual effect of addition and deletion, and the introduction of new Typed Clauses or the abolishment of Clauses behind the status quo are needed for the reality of the situation and the legal development.

An overview of the typed clauses of anti-unfair competition legislation in china and abroad

Given the particularity of the Typed Clauses, theoretical classifications or interpretations are not necessary for the corresponding judicial application. The typification discussion on Internet unfair competition behavior is started mainly through the cases. Started from both abroad and domestic dimensions, based on the domestic legislation analysis of Germany, the United States, Japan and China, inductive opinions were put forward, and the extension of its judicial application was explored.

\footnotetext{
${ }^{7}$ Jiang Ge (2014) Formal functions and substantive functions of the general terms of anti-unfair competition law. Studies in law and business, China.

${ }^{8}$ Wang Zejian (2001): “General Principles of Civil Law," China University of Political Science and Law Press, p. 292.
}

\section{An overview of typed clauses of anti-unfair competi- tion legislation abroad}

As one of the earliest anti-unfair competition law legislators, Germany enacted the first special anti-unfair competition law in 1896, which was revised several times from then on. The latest substantial additions and deletions against the anti-unfair competition law were made in 2004. The Typed Clauses of the anti-unfair competition are also reflected in the relevant provisions, with examples of improper trade practices regulated in Article 4, misleading transactions in article 5 and comparative advertising in Article 6, and unreasonable Annoyance (behavior) in Article $7^{9}$. The title "improper" has appeared in the new law, whereas its specific meaning is not defined, while unfair competition behavior examples are listed by Typed Clauses. The American anti-unfair competition law originated in state law. For quite a long time, it is the common law of states protected competitors against unfair competition in the market. But this situation has been changed after the promulgation of "Lanham law", the Federal Trademark Law, since 1946. Although the Act is a federal Trademark Law, its article 43(1) states a wide range of content to curb unfair competition, and therefore, Article 43(1) of Federal-level "Lanham law" has become parallel with the state-level anti-unfair competition law. The Typed Clauses of anti-unfair competition are mainly related to counterfeiting, false advertising, commercial slander, desalination, stealing the commercial value of others, encroaching on other people's business secrets and infringing upon the image of others.

Japan has established a legal system for an anti-unfair competition long ago and has accumulated experience and insights in legislation and practice. Anti-unfair competition legal system of Japan was formally established in 1934. The regulatory approach that the law adopted has been based on civil remedies and assisted with corresponding criminal sanctions. The law was labelled as typical private law. In the legislative model, Japan adopted a separate system, that is, legislation towards the monopoly, anti-competitive practices, and unfair competition practices was proposed respectively, both of anti-monopoly, anti-competitive practices law and anti-unfair competition law stand side by side. As a non-recognition of the general clauses country, Japan's "unfair competition prevention law" enumerates several types of unfair competition by adopting a simple list of legislative methods. In judicial practice, the law, on the one hand, was applied to specific cases through expansion interpretation, on the other hand, it was relieved by the tort law.

\section{An overview of types clauses on china 's anti - unfair competition legislation}

From Article 5 to Article 15 in Chapter 2 of the Anti-Unfair Competition Law of China, it stipulates the Typed Clauses that regulate acts of unfair competition. In the academic study of unfair competition, the above behavior is divided into six categories, namely, counterfeiting, false propaganda, commercial slander, infringement of trade secrets, improper prize-giving sales, and commercial bribery ${ }^{10}$. The legislative paradigm of unfair competition behavior emphasizes the "behavior legislation" model, rather than the pure "subject legislation" model or "definition legislation" model. That is to say, for the legislative model of unfair competition typification, the "subject-

\footnotetext{
${ }^{9}$ Gesetz gegen den unlauteren Wettbewerb, UWG (2010) Taiwan Fair Trade Commission, Unfair Competition Prevention Act of Germany.

${ }^{10}$ Case source (2010) Han Chifeng and others: "Classic Chinese and Foreign Cases of "Unfair Competition Law, Intellectual Property Press, USA, p. 39.
} 
means-purpose" paradigm should be used, and the legislative behavior- design cannot be carried out alone ${ }^{11}$.

\section{Summary}

This paper analyzes the Typed Clauses of unfair competition behavior both at home and abroad, and finds out that: First, the typification of unfair competition has both coincidence and differences, which reflects the focus of different national legislative regulations. Second, the typification of unfair competition is gradually changing from simplification to complex and comprehensive regulatory type; Third, co-ordination and convergence of the Typed Clauses and the General Clauses is the national legislation problem to be solved, and extended interpretation of the Typed Clauses is also needed to be focused on in the Internet environment

\section{Study on the conditions of substantive confir- mation of unfair competition in china 's inter- net environment}

\section{An analysis of the typed clauses of peoples republic of china anti - unfair competition law and case interpre- tation}

Counterfeiting: Counterfeiting is regulated by Article 5 of the Anti-Unfair Competition Act in China ${ }^{12}$. New forms and contents are developed for counterfeiting by the new environment. The collision between the Internet environment and the traditional unfair competition produces counterfeiting acts like domain name cybersquatting, site confusion and so on. Take the Blue State v. Guxiang case in 2011 for example, Zhang Hua, the founder of Blue State Company, is an expert with high reputation in the field of water electrolysis. However, Family Company bought the keyword "Zhang Hua Electrolyzed Water" from Google website run by Guxiang Company for advertising and promotions without Zhang's permission. On knowing the news, Blue State sent Lawyer's Letter to Guxiang twice, but Gu Xiang did not stop providing search service for the Family company. The Court deems that Guxiang does not have any fault before receiving Lawyer letter from Blue State. Thus Guxiang does not need to bear legal responsibility. However, after receiving the lawyer letter, Guxiang did not take appropriate measures to prevent the continuing infringement and expanding losses, Guxiang Company has a clear subjective fault, and objectively constitutes the help for unfair competition, and thus should bear legal responsibility with the family company ${ }^{13}$.

False propaganda: According to Clause 1, Article 9 of the Anti-Unfair Competition Law of Peoples' Republic of China, the operator shall not use advertisements or other methods to mislead consumers about the quality, the composition, the performance, the usage, the

\footnotetext{
${ }^{11}$ Wang Zuoquan, Wang Liming (2006) Legislative Model and Typification Problems of China's Anti Unfair Competition Law" New Heights, China.

${ }^{12}$ Quotes from Article 5 of The Anti-Unfair Competition Law of the People's Republic of China.The operator shall not use the following improper means to engage in market transactions and cause damage to competitors: (a) counterfeit other's registered trademark; (b) unauthorized use of the name, packaging, decoration, or unauthorized use of similar name, packaging, decoration of a well-known commodity to cause misleading; (3) unauthorized use of the name of an enterprise or name of the person to cause misleading; (d) forged or fraudulent use of certification, famous lables or other quality certifications on the commodity, or forge its origin to cause misunderstanding and false understanding about the quality.

${ }^{13}$ Dispel the Smoke of the Internet war-Classified Analysis of Typical Case of Internet Unfair Competition, adapted from http://www.zhichanli.com/
}

producer, the expiry date, and the origin of the goods. The focus of the clause is that given the freedom of expression is a fundamental right protected by Constitution of the Peoples' Republic of China, the Court, when interpreting the application of the norms mentioned above, shall take all these into consideration to avoid the consequences that go against the protection of the fundamental rights ${ }^{14}$. In the false propaganda case of Guangzhou Pharmaceutical Group v. Jia Duo Bao, the court holds that changing-name advertising slogan of Jia Duo Bao constitutes false propaganda according to Clause 1, Article 9 of the anti-unfair competition law of Peoples' Republic of China. The JDB company is ordered to stop using the slogan "national leading sales of red cans of herbal tea has changed its name into Jia Duo Bao herbal tea", "the original red cans herbal tea Wanglaoji has changed its name into JDB herbal tea," immediately, and publicity items JDB use for advertising promotion shall be destroyed immediately. JDB is sentenced to pay Guangzhou Pharmaceutical Group 10 million RMB for economic loss, besides the reasonable cost of 810 thousand RMB, and make a public apology in the "Guangzhou Daily" and the people.cn home page ${ }^{15}$. The emphasis of false propaganda is that false descriptions have misled the consumers in the market and harmed the interests of other competitors rather than that competitors have made false descriptions of products, services, or business activities themselves ${ }^{16}$.

Commercial slander: Commercial slander is stipulated in Article 14 "Anti-Unfair Competition Law of the Peoples' Republic of China" as operators shall not fabricate, spread false hypocrisy, and damage the commercial reputation or commodity reputation of competitors. Legal elements that constitute the behavior of commercial slander are: 1 , the main body of behavior must have the operator identity; 2 , the objective content of the behavior is expressed as fabricating and spreading false hypocrisy. 3 , the main body of behavior has subjective intent or fault. 4 , the object of performance that is the victim suffers business losses or commercial interest infringement. Organic integration between commercial slander and the Internet environment is obvious. In 2014, "360 buttoned bodyguards" software commercial slander case is one of the typical representative, with the case, the Supreme People's Court clear the Internet environment in the commercial slander behavior rules. The essential element is whether the behavior of the relevant operator misleads the commercial reputation of the competitor or the reputation of the goods. The Supreme People's Court pointed out that the operator for business purposes for others to conduct business criticism, in particular, to be careful to pay attention to obligations; the healthy development of the Internet requires an orderly market environment and clear rules of market competition as a guarantee, and freedom of competition and freedom of innovation must not violate the legitimate rights and interests of others. In the present case, the Supreme People's Court clarified the relationship between technological innovation, free competition and unfair competition in the Internet market ${ }^{17}$.

\section{Interpretation of the amendment of china's "anti-un- fair competition law": new problems with internet}

The need for typed clauses under the internet domain: Typed Clau-

${ }^{14}$ Carle Larenz (2003) Methodology of law, Commercial press, China, p.216219

${ }^{15}$ Guangzhou City Intermediate People's Court (2012)-Hui Zhongfa Zhi Minchu No. 263 civil judgment.

${ }^{16}$ Li Mingde (2008) On Intellectual Property Law, Law Press, China, p. 299 ${ }^{17}$ Introduction of 10 Intellectual Property Cases of Chinese Courts in 2014 , online version of China Intellectual Property, http://www.chinaipmagazine. com/news-show.asp?id=13491, 2015-04-21. 
ses in China's current "Anti-unfair Competition Law" do not specify the new Internet issues, and whether the expansion of Typed Clauses in the field of Internet is necessary to deal with the problem is still to be discussed. In the revision of the law some scholars suggested to add a list of some new ways of competition and business model on the Internet era, such as how to regulate malware, spike, hypertext links, pop-up ads, domain name cybersquatting, and technology isolation, PPC, tampering or overlaying web pages and so on. This suggestion is beyond reproach, but if the new list is made, it will not necessarily list exhaustive new types of unfair competition and is not conducive to the stability and sustainability of the law. More importantly, with the Internet as a new medium, a lot of unfair Internet competition is just covered by the name of Internet competition, while its connotation or nature is still unfair competition; so many experts also believe that because the Internet is only a form of existence, it does not have the necessity of a separate legislative enumeration.

Criteria for the determination of illlegal income: Illegal income usually refers to the property acquired by the person who engaged in the illegal activity and other illegal property. The illegal gains have the characteristics of illegal means, the economy of the illegal gains and the strictness of the determination. Given the illegal income is gained mainly through the two ways of criminal and non-criminal approach, and unfair competition in the field of economic law has more government regulations, so the illegal income discussed in this article only refers to the non-criminal approach or illegal income in the sense of administrative law. If the perpetrator violates the "Food Sanitation Law" and runs an illegal business to obtain illegal benefits, or the perpetrator violates the "Price Law" and causes consumers or other operators to pay more to obtain their illegal interests. "Administrative Punishment Law" stipulates that "confiscation of illegal income" is one of the statutory categories of administrative penalties, which is a statutory sanction for the administrative perpetrator and is executed by the administrative authorities at all levels. The refinement of the standards in the Internet field is still the problem for identification and execution. The discretion of the court in determining the standard is of the utmost importance. Therefore, the determination of the upper limit is the barrier to the new form and the specificity in the judicial practice. The specific amount still needs to be analyzed according to the specific cases.

Discussion on the boundary of technological innovation and unfair competition: The competition behavior includes the elements of two conflicts of imitation and innovation. Both competition law and intellectual property law have the functions of defining imitation boundary and protecting the innovation achievement, and thus both are the legal norms to adjust the competitive behavior. Intellectual property law protects legitimate behavior by protecting innovation and empowering innovation achievements, and competition law promotes and protects innovation by protecting legitimate competition and encouraging free competitions. Although intellectual property law and competition law belong to different types and different natures of law, there is a common goal - to protect innovation and promote competition. Intellectual property law should, therefore, be incorporated into the competition law system to be understood and applied. While paying attention to the application of the intellectual property system, China should also pay attention to the role of competition in promoting innovation and form a unified competition policy to guide and coordinate the cooperation between intellectual property law and competition law to stimulate and protect innovation, and to better balance the relationship between innovation and imitation, competition and monopoly, private interests and social and public interests. The innovation of the Internet field involves multiple levels, not only in the level of technological innovation but also an innovation of business model, business philosophy, the administrative intervention of multiple innovations, so there is more difficulty and complexity in distinguishing between technological innovation and unfair competition. The development of the Internet economy makes the boundaries of illegality more and more blurred. While there seems to be no competitive relationship between two completely different types of products and services on the surface, but in fact, there may be a competitive relationship between the two platforms ${ }^{18}$.

\section{Analysis of the types of new unfair competition in in- ternet environment}

In Chapter II of China's "Anti-Unfair Competition Law," it listed 11 kinds of unfair competition, including exclusion, abuse of administration, forced sales, collusion, counterfeit name, secret bribery, and false propaganda, breach of secret, low-price sales, prize sales, and damaged reputation. This article summarizes the types of unfair competition, but because the development of the Internet field has accelerated and changed the pace of behavior, the currently typed clauses have been unable to meet the development and induction needs of unfair competition behavior. There is an urgent need to regulate in practice and general provisions, but also to amend the law for the current unfair competition to be regulated (Figure 1).

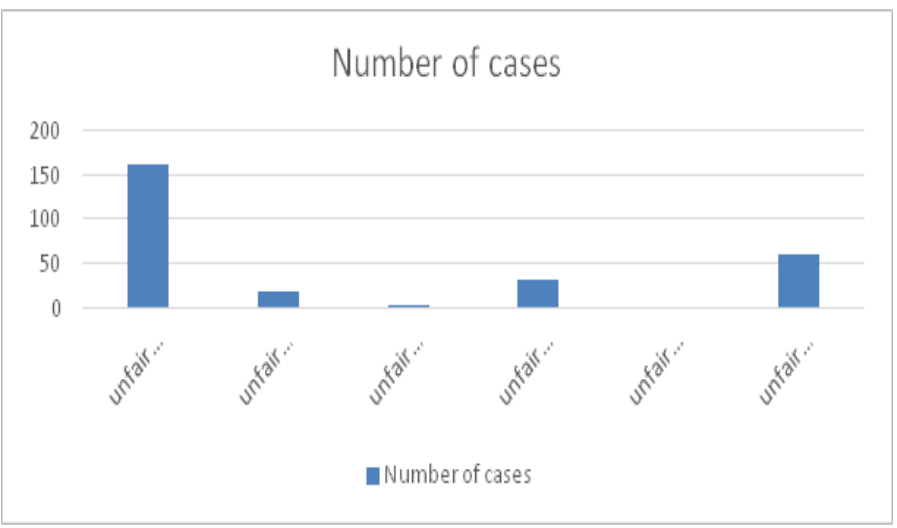

Figure I Unfair competition + keyword search results.

Source Based on the search results of pkulaw.cn

The typological approach here is different from the mere application of the typified clauses, but rather a formal classification of new forms of unfair competition for further search of applicable terms. The typification of new unfair competition in China is mainly to use the search platform of pkulaw.cn to analyze the cases of unfair competition to set up keywords to evaluate the number of different types of cases. Keywords are set as "unfair competition + network", "unfair competition + Internet", "” unfair competition + website "," unfair competition + domain name "," unfair competition + search "," improper competition + software ", and number of cases are 163, 19, $4,34,3$ and 62 respectively ${ }^{19}$.

${ }^{18}$ (2015) Revision of Anti-Unfair Competition Law Targeting at Internet, Legal Weekly.

${ }^{19}$ Adopting the search method of pkulaw.cn, among all the judicial cases of pkulaw.cn, a total of 4442 documents were retrieve when "unfair competition" were searched as the cause from jurisprudence and referee documents. To narrow the scope of the search, this report first added keywords, searched on 2015/7/6. 
By analyzing Figure 2, it can be found that China's new Internetbased unfair competition cases are mainly done after 2000, especially after 2005, which shows a trend of a blowout, and in recent years it continues to maintain sustained growth momentum, which is the inevitable trend of the development of the Internet age. As the above information is only the data of the selected cases, in order to grasp more fully the new unfair competition case data, further search needs to be done by using the big data platform of the referee documents ${ }^{20}$. According to the year of their trial, the data shows that the new unfair competition cases have been increasing year by year since 2011, among which the growth rate of 2011 2013 is relatively stable, with an average annual growth of about 100, but there is an explosive growth in 2014. In the same period of 2013, the number of cases has nearly doubled. The unfair competition in the Internet field presents a surprising number and an increasing rate, which means there is an urgent need to follow up and resolve in the judicial practice (Figure 3).

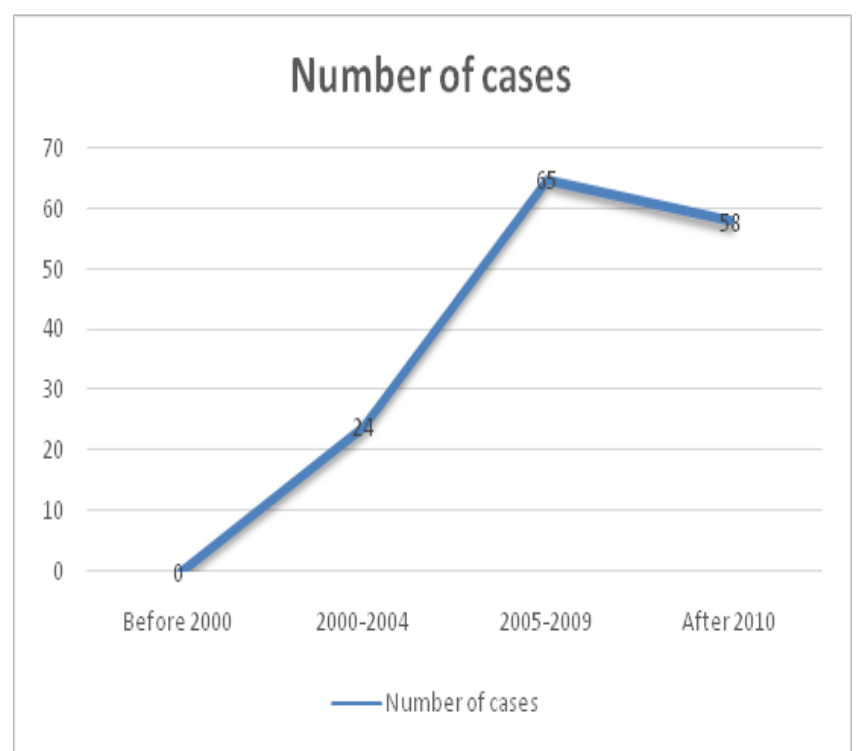

Figure 2 Data Trends of New Unfair Competition Cases.

Source According to the search results of pkulaw.cn, the case data after 2010 shows: the case data after 2010 contains only the data from 2010 to 2014 , but the case in 2015 only contains three cases before March 2015

Based on the above analysis of the new unfair competition behavior, about how to classify it in the Internet environment, this paper attempts to give a typed analysis for the new unfair competition in the Internet environment on the basis of combing the theoretical mainstream view and data base, thus to cope with the increasing number of emergencies in judicial practice and the increasing number of illegal cases, hoping that Typological thinking will provide a more convenient solution.

Safety products: Safety products mainly include security software, security plug-in cases, and the specific behaviors include hindering the software installation and operation, inducing to uninstall or to maliciously uninstall software or to install malicious plug-ins. This type of behavior is mainly the use of security software or plug-in to hinder the installation and use of other software in the installation

${ }^{20}$ When entering the keywords "Unfair competition + network", a total of 8618 articles were found, covering five types of judgments, rulings, decisions, mediation and other documents, including six categories of criminal, civil, intellectual property, administrative and national compensation cases. and use with the purpose of unfair competition. The 62 cases found by pkulaw.cn by searching the keywords of "unfair competition+ software" all belong to this type which is also the major type. In the "2014 Intellectual Property Case Summary" published by Supreme People's Court, it pointed out: in the retrial of the unfair competition dispute case among applicant Qihoo and the respondent Baidu.com, BIDU and the first trial defendant Qizhi [(2014) Min Shen No. 873], the Supreme People's Court pointed out that security software has a priority in the computer system, and they should be prudent to use this "privilege". The intervention to their users and other service providers should be aimed "to achieve its necessary function" as a prerequisite. In the absence of reasonableness and necessity, when implementing interference to others without permission, it then constituted unfair competition.

\section{NUMBER OF NEW TYPES OF}

5000

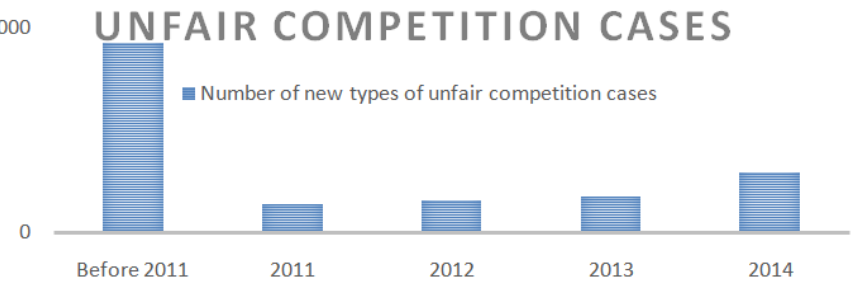

Figure 3 Summary of new types of unfair competition cases based on big data platforms.

Data Description, Before 20I I, the data covers a wide range, and as long as they contain search keywords, they are included in this range. However, because the data platform did not aggregate, the 2015 data finds only five documents, so they are not included in the scope of comparison

Source big data platform of Referee instruments

Website business: This category mainly includes violations of trade secrets, slander, unauthorized use of relevant contents and other acts. Take the typical case of Qihoo $360 \mathrm{v}$. Tencent as an example, freedom of competition and freedom of innovation must not violate the legitimate rights and interests of others. The Supreme Court determined that the focus of the dispute in the trial was: between the two competitive enterprises when one party was not telling the truth but fabricating the facts, damaging the other party's business reputation and the reputation of goods, does it constitute unfair competition and commercial slander? Article 2 and Article 14 of the Anti-Unfair Competition Law of the People's Republic of China stipulate that the operators shall comply with the principles of voluntariness, equality, fairness, and honesty in the market transactions and abide by the recognized business ethics. The operators shall not fabricate facts, spread false facts, or damage the business reputation and commodity reputation of competitors. Therefore, between the enterprises with a competitive relationship, when one party was not telling the truth but fabricating the facts, it has an obvious intent of unfair competition, which damages the business reputation and commodity reputation of the other party, and thus constituting a commercial slander.

Search service: The survey of "China Internet Development Statistics Report" shows that: as of June 2016, the number of China's search engine users has reached 593 million, with a utilization rate of $83.5 \%$, which is 26.35 million more than the number by the end of 2015 , with an increase of $4.7 \%$; The number of mobile phone search users reached 524 million, with a utilization rate of $79.8 \%$, which is 46.25 million more people than at the end of 2015 , with an increase 
of $9.7 \% \%^{21}$. The development trend and characteristics of search engine services are as follows: First, diversification. Search service provides not only a single text link but a combination of multiple factors, including pictures, forms, applications, etc.; Second, personalization. They can explore the user's preferences, social choices, and location sharing from the user's search records; Third, transformation. The service has transformed to become a comprehensive service provider for enterprises and a one-stop life service platform for users. The types of unfair competition involved in the search service category mainly include the two aspects of human intervention of keyword search and control of vertical search technology: First, the problem of human intervention for keyword search can be attributed to counterfeiting, false propaganda or commercial defamation. In the case of Letao V. Okbuy Google, when keying in the word "letao" in the Google search engine, a commercial advertising saying "when buying sports shoes, Okbuy Is better than Letao "will appear in a prominent position, so Letao sued okbuy.com, Google Information Technology (China) Co., Ltd., Beijing Feixiangren Information Technology Co., Ltd., Beijing Gu Xiang Information Technology Co., Ltd. on the grounds of corporate reputation violation and unfair competition. The link is a sponsored link, that is, an ad link, and the link will lead directly to the competitor's website ${ }^{22}$. This behavior is taking advantage of Letao's business reputation to seize its business opportunities and give priority to show their own website links. These series of acts are contrary to the principle of good faith and recognized business ethics, constituting unfair competition. Second, the control to the use of vertical search technology.

Concept definition: vertical search is a professional search engine, and this search service provides users with targeted information search, usually for a particular area, a specific population or a specific need or specific information, such as food and beverage, and tourism. Vertical search engine information mainly comes from specific websites in a certain industry. Such services can, to a certain extent, solve the problems of general search engines, such as overloaded information, inaccurate query, and lack of detail ${ }^{23}$. Shanghai Han Tao Information Consulting Co., Ltd. v. Alabang Juxin (Beijing) Technology Co., Ltd. and other unfair competition dispute cases. The plaintiff and the defendant were operators of "dianping.com" and "ibang.com" respectively. The plaintiff claimed that the defendant has been copying the contents of "dianping.com" through the "ibang. com" for a long time to obtain improper page views and competitive advantages. The defendant argued that they provided a vertical search service that met the requirements of a general display model of the search service industry. Beijing First Intermediate People's Court held that the use of vertical search technology for specific industry website information should be controlled within a reasonable range, but beyond this range, it will constitute unfair competition. When "dianping.com" is using the content of "Ibang.com," the network users do not need to enter dianping.com to get enough information, causing the corresponding content of comments on the "dianping.com" to be replaced by the content of ibang.com. Taking into consideration that vertical search engine technology can provide more accurate search services for network users, and will promote the development of the

${ }^{21}$ (2016) China Internet Network Information Center (CNNIC), the 38th Statistics Report of China Internet Development.

${ }^{22}$ In the case of "Letao" v. "okbuy" for unfair competition, "Letao" received 100,000, 2010-11-29.

${ }^{23}$ pkulaw.cn, (2011) zhongminzhongzi No. 7512, the Unfair Competition Case of Shanghai Hantao Information Consultancy Co., Ltd and Aibang Juxin (Beijing) Technology Co., Ltd on whether vertical search can constitute a behavior of unfair competition. search engine industry, the technology itself is not illegal. However, the legitimacy of the technology does not mean that the use of vertical search technology can be without any restrictions. Therefore, Beijing First Intermediate People's Court determined that the defendant's acts constitute unfair competition, and ordered compensation of 500,000 yuan for the plaintiff ${ }^{24}$.

Domain names: In Article IV of "The interpretation of Several Issues on the Trial of Civil Disputes Involved in Computer Network Domain Names" by Supreme People's Court, it lists a number of cases that constitute a form of infringement or unfair competition, including: the defendant's domain name or its main part has conducted a duplication or imitation, or translation, or transliteration of the registered trademark; or it is the same or similar to the registered trademark or the domain name of the plaintiff, which is sufficient to cause the public to be mistaken; the defendant has no rights to the domain name or its main part and has no reason for the registration and use of the domain name. The unfair competition appeal case between Beijing Quna Information Technology Co., Ltd. and Guangzhou Quna Information Technology Co., Ltd ${ }^{25}$. The Guangzhou Company has used the previously registered domain name "quna.com," but the website of Beijing company belongs to a unique name of a wellknown service provider, and they registered the domain name "qunar. com." There is only a difference of " $\mathrm{r}$ " between the two domain names, constituting a similar domain name. The focus of this case is whether the acts of the Guangzhou Company using domain names of "quna.com," "123quna.com", and "mquna.com" constitute a violation of domain name interests of the Beijing Company. According to the provisions of Article IV of "The interpretation of Several Issues on the Trial of Civil Disputes Involved in Computer Network Domain Names" by Supreme People's Court, if the registration or the use of the domain name of the defendant meets the following conditions, then it constitutes infringement or unfair competition: 1 . The civil rights and interests requested by the plaintiff are legal and valid; 2 . the defendant's domain name or its main part constitutes duplication or imitation, or translation, or transliteration of the plaintiff's well-known trademark; or it is the same or similar to the registered trademark or the domain name of the plaintiff, which is sufficient to cause the public to be mistaken; 3 . the defendant has no rights in the domain name or its main part and has no reason for the registration and use of the domain name; 4 . the defendant has malicious intent regarding the registration and use of this domain name. But the court believed that they could coexist for a long time, and it does not constitute unfair competition. The reasons are: First, the domain name is globally unique. Due to the limited length of a domain name, the maximum capacity of global domain name registration is no more than 4.3 billion. There is no economic benefit to banning the registration of similar domain names. Second, a domain name is identified by the computer system which can accurately distinguish a highly similar domain name, without any confusion. It should be noted that both parties have rights to a domain name from a legitimate source, so they need to tolerate each other, respect each other, and seek long-term coexistence. One party cannot deprive the other's living space because of its success and popularity; the other party cannot make malicious use of the other party's good reputation to seek improper business interests. Therefore, even though the Guangzhou company has the right to continue to use the domain names of "quna.com", "123quna.com", and "mquna.com", they also

${ }^{24}$ Beijing City Intermediate People's Court issued ten typical cases of Internet unfair competition, http://news.ename.cn/yuming20140624_56403_1.html.

${ }^{25}$ (2013)Guangdong Higher Peoples Court, Yue Gao Fumin San Zhongzi No. 565 civil judgment. 
have the obligation to add identification marks on the search links and website related to their domain name, so that consumers will recognize the differences between the above domain names and the well-known domain names of the Beijing company such as qunar.com ${ }^{26}$.

Other types: In addition to the above-mentioned major types, the new unfair competition is also involved in online games, e-mail addresses, e-commerce, and instant messaging software. The data from the Complaints Platform of www.315online.com shows that in 2015, there was a total of 26700 cases of network service complaints, accounting for $41.5 \%$ of the total amount of complaints throughout the year ${ }^{27}$. In recent years, what business has become a major field of infringement, and the unfair competition content is mainly infringement through some emerging media, such as Taobao's widespread "click farming", meaning that the shop owners will hire people to pretend to be the buyers to improve the ranking and sales to expand their comments and sales to attract customers. Article 19(4) of the Measures for the Administration of Online Transactions stipulates that: "The sales and services of operators of the network business shall be done in accordance with the provisions of the Law on Anti-Unfair Competition, .......they must not conduct any unfair competition by using network technology or other media: (4) to enhance business reputation for themselves or to others through ways of fictitious transactions or deleting adverse comments." According to Article 53 of the Measures for the Administration of Online Transactions: In violation of the provisions of Article 19(4), business owners shall be punished in accordance with the provisions of Article 24 of the Anti Unfair Competition Law." Article 24 of Anti-Unfair Competition Law of the People's Republic of China" reads: "If operators use advertising or other methods to cause misleading or false promotion, supervision and inspection departments should order them to stop the illegal acts, eliminate the impact, and can implement a fine of no less than 10,000 yuan but no more than 200,000 yuan, depending on how serious the

${ }^{26}$ See "quna.com" for unfair competition dispute case of previously registered domain name, 2015-04-20, last access: 2015-06-17; pkulaw.cn, (2013) Yue Gao Famin San Zhongzi No. 565 civil judgment, unfair competition dispute appeal case between Beijing Quna Information Technology Co., Ltd. and Guangzhou Quna Information Technology Co., Ltd.

${ }^{27}(2015)$ Online shopping is still the hardest hit to consumer infringement while we chat business causes new difficulties for supervision. case was." Based on these requirements, the "click farming" behavior needs to be regulated and punished.

\section{Conclusion}

This paper discusses the topic of unfair competition under the background of the Internet environment, and meanwhile, from the research perspective of "typed clauses", it attempts to identify the unfair competition, and then it analyzes the development and transformation of "typified clauses" both at home and abroad, focusing on how to use "typed clauses" to deal with new types of unfair competition in China's Internet world. The research shows that: First, traditional types of unfair competition, such as counterfeiting, false propaganda, commercial slander, remain in the Internet world and typed clauses can be applied to make adjustments; Second, the Internet environment has also created a new type of unfair competition, but China's judicial practice usually adopt general clauses for judgment. Third, China's judicial practice has conducted a deeper exploration of the boundary definition between technical innovation and unfair competition. Based on study of typical cases, it determines that a healthy development of the Internet requires an orderly market and definite competition rules, and freedom of competition and freedom of innovation must not violate the legitimate rights and interests of others; Fourth, China's new unfair competition cases are classified into many categories, such as security products and website business, which leaves significant potential and value for further study and research.

\section{Acknowledgements}

This paper is sponsored by K.C.Wong Magna Fund in Ningbo University and Zhejiang Province Philosophy and Social Sciences Planning research project (No 17NDJC112YB) and 2014 National Social Science Fund key topic "Research on Farmer Rights in the Perspective of Intellectual Property Protection of Plant Genetic Resources" (No.14AFX022) and Ningbo Soft Science Project(No 2014A10022).

\section{Conflict of interest}

The author declares that there is no conflict of interest. 